\title{
Ixabepilone: a new treatment option for the management of taxane-resistant metastatic breast cancer
}

This article was published in the following Dove Press journal:

Cancer Management and Research

23 July 2009

Number of times this article has been viewed

\section{Marta Vallee Cobham Diana Donovan}

Weill Cornell Breast Center, Cornell University/New York-Presbyterian Hospital, New York, NY, USA
Correspondence: Marta V Cobham Division of Hematology/Oncology, Weill Cornell Breast Center Cornell University/New York-Presbyterian Hospital, 425 East 6Ist St, 8th Floor New York, NY 1002 I USA

$\mathrm{Tel}+\mid$ 2 I 2-82 I-0780

Fax + | 2| 2-82|-0758

Email mac2034@med.cornell.edu
Abstract: Ixabepilone (Ixempra ${ }^{\circledR}$; Bristol-Myers Squibb) is a novel microtubule stabilizing agent recently approved for the treatment of metastatic breast cancer (MBC). This article focuses on considerations for ixabepilone administration and adverse event (AE) management, drawing from the biomedical literature indexed in PubMed, published abstracts from the American Society of Clinical Oncology annual meetings, and the manufacturer's prescribing information for ixabepilone. Administered as monotherapy or in combination with capecitabine in clinical studies, ixabepilone demonstrated positive clinical response rates, prolonged progression-free survival, and a favorable safety profile in patients with MBC. Treatment-related AEs were predictable and manageable with dose modification, treatment interruption, and active management. As ixabepilone undergoes development in earlier lines of breast cancer therapy and in other solid tumors, oncology nurses will encounter more and more patients receiving ixabepilone therapy. If nurses are acquainted with the unique management strategies associated with ixabepilone treatment, as detailed herein, patients are more likely to receive the full benefit of therapy.

Keywords: breast cancer, chemotherapy, microtubule-stabilizing agent, ixabepilone, adverse events, patient management

Breast cancer is the most frequently diagnosed cancer among women. ${ }^{1}$ It is estimated that in 2008, more than 182,000 women in the United States were diagnosed with breast cancer and more than 40,000 died from the disease. ${ }^{2}$ At diagnosis, the majority of women (52\% to $61 \%$ ) have localized tumors; the remainder have tumors that have spread regionally ( $31 \%$ to $36 \%$ ) or have distant metastases ( $6 \%$ to $9 \%){ }^{2}$ The 5 -year survival rates are high for female breast cancer that is localized at diagnosis $(98 \%)$, but rates are lower for breast cancer that is diagnosed at regional and distant invasive stages (approximately $84 \%$ and $27 \%$, respectively). ${ }^{3}$

Metastatic breast cancer (MBC) is essentially incurable, and chemotherapy is commonly prescribed with the goals of maximizing patient quality of life, preventing and/or relieving symptoms, and prolonging survival. ${ }^{4}$ Unfortunately, resistance to common chemotherapeutic agents (eg, anthracyclines and taxanes) is a major cause of treatment failure. ${ }^{5-7}$ Anthracycline and taxane use in the adjuvant and neoadjuvant settings is increasing the proportion of breast cancer patients who are resistant to these agents in the metastatic setting. ${ }^{8}$ Multidrug resistance (MDR), defined as a cross-resistance to structurally unrelated compounds, is thought to occur through a variety of mechanisms, including alterations or mutations in apoptotic pathways or drug targets. Moreover, tumor cells frequently express higher-than-normal levels of drug efflux proteins, allowing the cells 
to reduce intracellular drug concentrations to nontoxic levels. A wide variety of cytotoxic and targeted anticancer agents are susceptible to this mechanism of drug resistance. ${ }^{9-11}$ Treatment resistance represents a significant challenge to healthcare professionals and their patients in the management of MBC. ${ }^{12}$ Thus, development of improved cytotoxic agents that effectively evade these resistance mechanisms is critical.

The epothilones, a novel class of antineoplastic microtubule-stabilizing agents (MSAs), provide a promising alternative to taxane therapy. Like the taxanes, epothilones stabilize microtubules by binding to the $\beta$-tubulin subunit of the $\alpha, \beta$-tubulin heterodimer, which eventually induces tumor cell death. ${ }^{13,14}$ Importantly, however, the epothilones are structurally unrelated to the taxanes, and the two classes have different $\beta$-tubulin binding modes. ${ }^{15}$

Among the epothilones, ixabepilone (aza-epothilone B; Ixempra $^{\circledR}$; Bristol-Myers Squibb, Princeton, NJ, USA) is furthest along in clinical development. Ixabepilone possesses greater cytotoxic activity than taxanes in cell lines that overexpress drug efflux transporters (multidrug resistanceassociated protein [MRP]-1, P-glycoprotein [Pgp], or breast cancer resistance protein [BCRP]), as well as those that overexpress $\beta$-III tubulin, an isoform to which the taxanes cannot bind. ${ }^{10,16-18}$ Ixabepilone's antitumor activity and lack of cross-resistance with the taxanes has led to its extensive clinical testing in a wide variety of solid tumor disease states, many of which are characterized by resistance to established agents such as taxanes and anthracyclines.

The objectives of this article are to provide practicing oncology team members with a summary of efficacy and tolerability data from three key ixabepilone clinical trials, a discussion of management strategies for common ixabepiloneassociated adverse events (AEs), and a review of ixabepilone dosing and administration procedures. In addition to references for these three key clinical trials, sections on adverse events drew from the US prescribing information for ixabepilone and the published body of literature available on the PubMed, American Society of Clinical Oncology, and San Antonio Breast Cancer Society websites. Subject-specific literature searches were conducted, and preference for inclusion in this article was given to references with recent, well-designed data that were applicable to clinical practice, at the authors' discretion based on their own extensive clinical experience.

\section{Ixabepilone clinical data}

Ixabepilone has demonstrated considerable efficacy in $\mathrm{MBC}$ patients, even in those who are heavily pretreated and whose lesions have progressed after treatment with multiple therapeutic agents. In October 2007, ixabepilone received US Food and Drug Administration (FDA) approval for the treatment of locally advanced or MBC after failure of an anthracycline and a taxane (in combination with capecitabine) and as monotherapy after failure of an anthracycline, a taxane, and capecitabine. ${ }^{17}$ This approval was based primarily on two large clinical trials, BMS Studies 081 and 046. Study 081 was a single-arm phase II trial evaluating the efficacy of ixabepilone monotherapy $\left(40 \mathrm{mg} / \mathrm{m}^{2}\right.$ intravenous [IV] over 3 hours every 3 weeks) in $126 \mathrm{MBC}$ patients whose disease had progressed on anthracycline, taxane, and capecitabine therapy. ${ }^{19}$ Study 046 was a pivotal randomized phase III trial that evaluated the combination of ixabepilone $\left(40 \mathrm{mg} / \mathrm{m}^{2} \mathrm{IV}\right.$ over 3 hours every 3 weeks) and capecitabine $\left(1000 \mathrm{mg} / \mathrm{m}^{2}\right.$ orally twice daily for 14 days of a 3 -week cycle; $n=375$ ) versus capecitabine alone $\left(1250 \mathrm{mg} / \mathrm{m}^{2}\right.$ orally twice daily for 14 days of a 3-week cycle; $\mathrm{n}=377$ ) in 752 patients with anthracycline- and taxane-resistant MBC (strictly defined as recurrence within 4 months of the last dose in the metastatic setting or within 12 months in the adjuvant setting). ${ }^{20}$ Subsequently, a larger confirmatory trial (BMS Study 048) enrolled 1221 taxane- and anthracycline-pretreated MBC patients, $50 \%$ of whom met the resistance criteria defined in Study 046. Using the same treatment protocol as in Study 046 , the 048 trial compared progression-free and overall survival for patients receiving ixabepilone and capecitabine doublet versus capecitabine monotherapy. ${ }^{21}$ Efficacy data from these three trials are summarized in Table 1.

These three trials utilized the recommended ixabepilone dose of $40 \mathrm{mg} / \mathrm{m}^{2}$; the incidences of treatment-related AEs reported from Studies 046 and 081 are provided in Table 2. ${ }^{17}$ Serious AEs (grade 3 or 4 ) were by nature hematologic (ie, myelosuppression), dermatologic (skin reactions and nail disorders), pain-related, and gastrointestinal. The trials evaluating the ixabepilone/capecitabine doublet also noted grade 3 hand-foot syndrome; incidences were similar in the combination and single-agent capecitabine arms. ${ }^{20}$ Constitutional symptoms (fatigue/asthenia, fever, and neurological symptoms such as neuropathy) were common but were primarily of grades 1 or 2 in severity. ${ }^{19,20,22,23}$

\section{Contraindications and $\mathrm{AE}$ management strategies}

Over 1300 patients with MBC received ixabepilone therapy in the trials mentioned above, and while it was well tolerated by the majority of patients, ${ }^{19-21}$ some patients should not be treated with ixabepilone (Table 3). Ixabepilone monotherapy is contraindicated in patients with a neutrophil count below $1500 / \mathrm{mm}^{3}$ or a platelet count below $100,000 / \mathrm{mm}^{3}$. 
Table I Efficacy of ixabepilone in patients with $\mathrm{MBC}^{19-21}$

\begin{tabular}{|c|c|c|c|c|c|}
\hline \multirow[t]{2}{*}{ Study (Reference) } & \multirow[t]{2}{*}{ Patients } & \multirow{2}{*}{$\begin{array}{l}\text { Treatment } \\
\text { protocol }\end{array}$} & \multirow{2}{*}{$\begin{array}{l}\text { Overall response } \\
\text { rate - investigator } \\
\text { (IRRC) }\end{array}$} & \multicolumn{2}{|l|}{ Survival outcomes } \\
\hline & & & & Median PFS & Median OS \\
\hline $\begin{array}{l}\text { BMS 08 I } \\
(\text { Perez et al 2007) }\end{array}$ & $\begin{array}{l}\text { Women with advanced } \\
\text { breast cancer that had } \\
\text { been pretreated with } \\
\text { anthracyclines, taxanes, } \\
\text { and capecitabine }(n=\mid 13)\end{array}$ & $\begin{array}{l}\text { Ixabepilone } 40 \mathrm{mg} / \mathrm{m}^{2} \\
\text { (IV) on day I of a } \\
2 \text { I-day cycle }\end{array}$ & $18.3 \%(11.5 \%)$ & $\begin{array}{l}3.1 \text { months ( } 95 \% \mathrm{Cl} \\
2.7-4.2 \text { months) }\end{array}$ & $\begin{array}{l}8.6 \text { months }(95 \% \mathrm{Cl} \\
6.9-1 \mathrm{I} .1 \text { months })\end{array}$ \\
\hline $\begin{array}{l}\text { BMS } 046 \\
\text { (Thomas et al 2007; } \\
\text { Hortobagyi et al } \\
2008)^{20,21}\end{array}$ & $\begin{array}{l}\text { Women with advanced } \\
\text { breast cancer that had } \\
\text { been pretreated with } \\
\text { anthracyclines and were } \\
\text { resistant to taxanes } \\
(\mathrm{n}=752)\end{array}$ & $\begin{array}{l}\text { Arm I: } \\
\text { Ixabepilone } \\
40 \mathrm{mg} / \mathrm{m}^{2}(\mathrm{IV}) \text { on } \\
\text { day I of a } 2 \text { I-day } \\
\text { cycle }+ \text { capecitabine } \\
2000 \mathrm{mg} / \mathrm{m}^{2} / \text { day }(\mathrm{PO}) \\
\text { on days I-I4 of a } \\
2 \mathrm{I} \text {-day cycle }\end{array}$ & $42 \%$ vs $23 \%$ & $\begin{array}{l}5.3 \text { vs } 3.8 \text { months } \\
\text { (HR: } 0.78 \\
95 \% \mathrm{Cl} 0.67-0.91 \\
P=0.00 \mathrm{II} \text { ) }\end{array}$ & $\begin{array}{l}\text { I } 2.9 \text { vs II.I months } \\
\text { (HR: } 0.90 \text {; } \\
95 \% \mathrm{Cl} 0.77-1.05 ; \\
P=0.1936 \text { ) }\end{array}$ \\
\hline $\begin{array}{l}\text { BMS } 048 \\
\text { Hortobagyi et al } \\
2008)^{21}\end{array}$ & $\begin{array}{l}\text { Women with advanced } \\
\text { breast cancer that had } \\
\text { been pretreated with } \\
\text { anthracyclines and taxanes } \\
(\mathrm{n}=\mathrm{I}, 22 \mathrm{I})\end{array}$ & $\begin{array}{l}\text { Arm 2: } \\
\text { Capecitabine } \\
2,500 \mathrm{mg} / \mathrm{m}^{2} / \text { day } \\
(\mathrm{PO}) \text { on days I-14 of } \\
\text { a } 21 \text {-day cycle }\end{array}$ & $43 \%$ vs $29 \%$ & $\begin{array}{l}6.2 \text { vs } 4.4 \text { months } \\
\text { (HR: } 0.79 \\
95 \% \mathrm{Cl} 0.69-0.90 \\
P=0.0005 \text { ) }\end{array}$ & $\begin{array}{l}\text { I6.4 vs I } 5.6 \text { months } \\
\text { (HR: } 0.90 ; \\
95 \% \mathrm{Cl} 0.78-1.03 ; \\
P=0.1162 \text { ) }\end{array}$ \\
\hline
\end{tabular}

Abbreviations: $\mathrm{Cl}$, confidence interval; HR, hazard ratio; IRRC, independent radiology review committee; MBC, metastatic breast cancer; n/a, not applicable; OS, overall survival; PFS, progression-free survival; PO, per os (by mouth); IV, intravenous.

Ixabepilone monotherapy is also not recommended for patients with severe hepatic impairment; ie, those whose aspartate aminotransferase (AST) or alanine aminotransferase (ALT) levels exceed 10 times upper limit of normal (ULN), or those whose bilirubin levels exceed 3 times ULN. Moreover, moderate-to-severe liver dysfunction was associated with an increased risk of neutropenia-related death in patients treated with ixabepilone in combination with capecitabine. ${ }^{20}$ As such, ixabepilone in combination with capecitabine is contraindicated in patients with AST or ALT levels greater than 2.5 times ULN or a bilirubin level greater than ULN. In addition, dose reductions are recommended for patients with hepatic impairment and elevated AST, ALT, or bilirubin levels (Table 4). Furthermore, due to low water solubility, ixabepilone must be diluted in Cremophor EL (polyoxyethylated castor oil); therefore, ixabepilone therapy is contraindicated in patients with a history of severe hypersensitivity reactions to agents containing Cremophor EL. ${ }^{17}$ In the majority of patients, however, AEs associated with ixabepilone therapy can be effectively managed by dose reductions and supportive management techniques. Dose reduction and premedication strategies for the most common ixabepilone-related AEs are summarized in Table 5.

\section{Myelosuppression}

Myelosuppression, a common AE associated with cytotoxic chemotherapy, arises from drug-related disruption of bone marrow. ${ }^{24}$ It commonly manifests as neutropenia, leukopenia, anemia, and/or thrombocytopenia. In ixabepilone clinical trials of patients with $\mathrm{MBC}$, the most common hematologic AEs were neutropenia and leukopenia..$^{19,20,22,23}$ Most ixabepilone-induced neutropenia is short-lived and should not be a major cause of ddose reduction or treatment discontinuation. ${ }^{19,20}$

Diligent monitoring and intervention can prevent neutropenia from progressing to a severe grade and reduce the risk for infection. ${ }^{25}$ Patients who are older, have a poor nutritional status, or have a history of severe or febrile neutropenia are at greater risk for developing neutropenia; ${ }^{26}$ risk models may be useful in predicting those patients at greatest risk for developing neutropenia. ${ }^{27}$ To assess levels of myelosuppression, blood counts (including absolute neutrophil counts [ANC]) should be monitored weekly during the first two cycles of ixabepilone and as needed in subsequent cycles. Following the recommended contraindications for ixabepilone treatment, a patient should not begin a new cycle until the ANC is at least $1500 / \mathrm{mm}^{3}$ and the platelet count is at least $100,000 / \mathrm{mm}^{3} \cdot{ }^{17,28}$

Both neutropenia and leukopenia can be effectively managed with hematopoietic growth factors (eg, filgrastim). ${ }^{24}$ At the physician's discretion, as many as $12 \%$ of patients in clinical trials receiving ixabepilone monotherapy and $20 \%$ of patients receiving ixabepilone plus capecitabine were also administered supportive treatment with growth 
Table 2 Incidence of adverse reactions in MBC patients receiving ixabepilone ${ }^{17}$

\begin{tabular}{|c|c|c|c|}
\hline & \multicolumn{2}{|l|}{ BMS 046} & \multirow{2}{*}{$\begin{array}{l}\text { BMS 08I } \\
\text { Ixabepilone } \\
\text { monotherapy, } \\
n=I 26\end{array}$} \\
\hline & $\begin{array}{l}\text { Ixabepilone with } \\
\text { capecitabine, } \\
\mathbf{n}=369\end{array}$ & $\begin{array}{l}\text { Capecitabine } \\
\text { alone, } n=368\end{array}$ & \\
\hline \multicolumn{4}{|c|}{ Incidence of hematologic adverse events, grade 3 (grade 4) } \\
\hline Neutropenia & $32 \%(36 \%)$ & $9 \%(2 \%)$ & $31 \%(23 \%)$ \\
\hline Febrile neutropenia $^{\mathrm{a}}$ & $5 \%$ & $1 \%$ & $3 \%$ \\
\hline Leukopenia & $41 \%(16 \%)$ & $5 \%(1 \%)$ & $36 \%(13 \%)$ \\
\hline Anemia & $8 \%(2 \%)$ & $4 \%(1 \%)$ & $6 \%(2 \%)$ \\
\hline Thrombocytopenia & $5 \%(3 \%)$ & $2 \%(2 \%)$ & $5 \%(2 \%)$ \\
\hline \multicolumn{4}{|c|}{ Incidence of nonhematologic adverse events, total (grade 3/4) ${ }^{\mathrm{b}}$} \\
\hline $\begin{array}{l}\text { Peripheral neuropathy, } \\
\text { sensory }\end{array}$ & $65 \%(21 \%)$ & $16 \%(0 \%)$ & $62 \%(14 \%)$ \\
\hline $\begin{array}{l}\text { Peripheral neuropathy, } \\
\text { motor }\end{array}$ & $16 \%(5 \%)$ & $<1 \%(0 \%)$ & $10 \%(1 \%)$ \\
\hline Headache $^{c}$ & $8 \%(1 \%)$ & $3 \%(0 \%)$ & $1 \mathrm{I} \%(0 \%)$ \\
\hline Taste disorder & $12 \%(0 \%)$ & $4 \%(0 \%)$ & $6 \%(0 \%)$ \\
\hline Fatigue/asthenia & $60 \%(16 \%)$ & $29 \%(4 \%)$ & $56 \%(13 \%)$ \\
\hline Pyrexia $^{c}$ & $10 \%(1 \%)$ & $4 \%(0 \%)$ & $8 \%(1 \%)$ \\
\hline Myalgia/arthralgia ${ }^{c}$ & $39 \%(8 \%)$ & $5 \%(<1 \%)$ & $49 \%(8 \%)$ \\
\hline Musculoskeletal pain ${ }^{c}$ & $23 \%(2 \%)$ & $5 \%(0 \%)$ & $20 \%(3 \%)$ \\
\hline Nausea & $53 \%(3 \%)$ & $40 \%(2 \%)$ & $42 \%(2 \%)$ \\
\hline Vomiting & $39 \%(4 \%)$ & $24 \%(2 \%)$ & $29 \%(1 \%)$ \\
\hline Stomatitis/mucositis & $31 \%(4 \%)$ & $20 \%(3 \%)$ & $29 \%(6 \%)$ \\
\hline Diarrhea & $44 \%(6 \%)$ & $39 \%(9 \%)$ & $22 \%(1 \%)$ \\
\hline Constipation & $22 \%(0 \%)$ & $6 \%(<1 \%)$ & $16 \%(2 \%)$ \\
\hline Abdominal pain & $24 \%(2 \%)$ & $14 \%(1 \%)$ & $13 \%(2 \%)$ \\
\hline Anorexia $^{c}$ & $34 \%(3 \%)$ & $15 \%(1 \%)$ & $19 \%(2 \%)$ \\
\hline Weight decreased & II\% (0\%) & $3 \%(0 \%)$ & $6 \%(0 \%)$ \\
\hline Alopecia & $31 \%(0 \%)$ & $3 \%(0 \%)$ & $48 \%(0 \%)$ \\
\hline Skin rash ${ }^{c}$ & $17 \%(1 \%)$ & $7 \%(0 \%)$ & $9 \%(2 \%)$ \\
\hline Nail disorder ${ }^{c}$ & $24 \%(2 \%)$ & $10 \%(<1 \%)$ & $9 \%(0 \%)$ \\
\hline Hand-foot syndrome ${ }^{c}$ & $64 \%(18 \%)$ & $63 \%(17 \%)$ & $8 \%(2 \%)$ \\
\hline Skin hyperpigmentation & $11 \%(0 \%)$ & $14 \%(0 \%)$ & $2 \%(0 \%)$ \\
\hline
\end{tabular}

a National Cancer Institute Common Toxicity Criteria grading for febrile neutropenia ranges from grade 3 to 5 . Three patients (I\%) experienced grade 5 (fatal) febrile neutropenia.

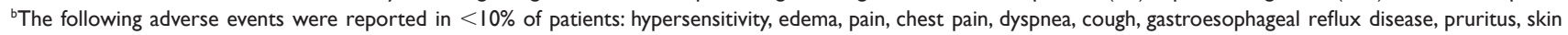
exfoliation, upper respiratory infection, febrile neutropenia, dehydration, insomnia, dizziness, increased lacrimation, and hot flush.

'No grade 4 reports.

factors (mostly filgrastim) for neutropenia. ${ }^{19,20,22,23}$ While these findings did not warrant a recommendation for prophylactic or routine use of growth factors during ixabepilone therapy, they should be considered in patients whose ANC drops below $1000 / \mathrm{mm}^{3}$. Under these circumstances, it is recommended that ANC be reassessed every 3 days until recovery and that the use of growth factors be considered with every subsequent cycle of ixabepilone. ${ }^{17}$ Notably, use of these growth factors may exacerbate treatment-related arthralgia and myalgia. ${ }^{29}$

\section{Neuropathy}

Neuropathy is a common AE associated with MSAs, including the taxanes and epothilones, possibly because microtubule stabilization may damage cells within peripheral nerves. ${ }^{30}$ The incidence of peripheral neuropathy varies depending on the drug 
Table 3 Contraindications for ixabepilone therapy ${ }^{17}$

Ixabepilone therapy is contraindicated in the following situations:

- Patient has known hypersensitivity to drugs formulated with Cremophor EL

- Patient has a baseline neutrophil count that is less than 1500 cells $/ \mathrm{mm}^{3}$

- Patient has a platelet count that is less than 100,000 cells $/ \mathrm{mm}^{3}$

- Patient exhibits mild hepatic impairment (combination therapy with capecitabine is contraindicated)

- Patient has aspartate aminotransferase or alanine aminotransferase levels that exceed 2.5 times the upper limit of normal, or

- Patient has bilirubin levels greater than the upper limit of normal

dose per cycle and the cumulative drug dose, the treatment schedule (eg, duration and frequency of administration), and any comorbidities such as the presence of diabetes mellitus or other endocrine disorders, concurrent administration of neurotoxic agents, alcoholism, or advanced age. ${ }^{30-32}$

The incidence and severity of chemotherapy-induced, neuropathy-related AEs in clinical studies is often difficult to interpret because of the subjectivity of patient reporting and the existence of multiple neuropathy grading scales. ${ }^{33}$ The FDA prefers that AEs be graded with the National Cancer Institute's Common Terminology Criteria for Adverse Events (CTCAE) (www.fda.gov), and the most recent ixabepilone MBC trials used this system (versions 2 and 3 ) to grade AEs, including neuropathy. $19,20,22,23$

Peripheral sensory neuropathy was the most common serious (grade 3/4) nonhematologic adverse event noted during the pivotal clinical trials of ixabepilone as a single agent or in combination with capecitabine (Table 2). ${ }^{17}$ Following the FDA approval of ixabepilone for marketing in the US, data from Studies 081, 046, and 048 were submitted to the European Medicines Agency (EMEA) in 2008 to gain approval for marketing in the European Union as well. In November 2008, however, the Committee for Medicinal Products for Human Use (CHMP) expressed a concern that the benefits of ixabepilone might not outweigh the risks. This negative opinion was based largely on the incidence and severity of peripheral neuropathy reported in the clinical trials (Table 2).
It is noteworthy that although the women in the 081, 046, and 048 studies had undergone multiple prior treatments with neurotoxic chemotherapy prior to their entering the ixabepilone clinical trials, the incidence of neuropathy associated with administering ixabepilone every 21 days was similar to incidences observed with administering the taxanes every 21 days (Table 2; rates of taxane-induced peripheral neuropathy ranged from $2 \%$ to $33 \%$ with Cremophor EL-based paclitaxel, 1\% to 9\% with docetaxel, and $0 \%$ to $11 \%$ with nanoparticle albumin-bound paclitaxel [formulated without Cremophor EL]). ${ }^{30}$ Also worth noting is that although peripheral neuropathy is one of the more common and serious AEs associated with ixabepilone therapy, it is usually sensory in nature, transient, and reversible. Patients with grade 3 or 4 peripheral sensory neuropathy in the 048 confirmatory trial, all of whom were heavily pretreated with neurotoxic agents, improved to baseline in a median time of 6 weeks from onset. ${ }^{34}$ This AE could effectively be managed through dose reduction or treatment delay, which allowed patients to remain on study and continue to receive treatment. ${ }^{19,20,22,23}$

As is true with myelosuppression, early recognition of symptoms and provision of supportive care can effectively prevent severe events. ${ }^{30,35,36}$ Clinical assessments, including physical examinations, are presently the best method to assess drug-induced peripheral neuropathy. Baseline analyses of motor skills and regular neuropathy assessments will aid in identifying at-risk patients and ensure early recognition

Table 4 Recommended ixabepilone monotherapy dose adjustments for patients with pre-existing hepatic impairment ${ }^{17}$

\begin{tabular}{lllll}
\hline Condition & Transaminase levels $(\times$ ULN $)$ & Bilirubin level $(\times \text { ULN })^{\mathrm{a}}$ & Starting dose $^{\mathrm{b}}\left(\mathbf{m g} / \mathbf{m}^{2}\right)$ \\
\hline Mild hepatic impairment & AST and ALT $\leq 2.5$ & AND & $\leq 1.0$ & $40^{\mathrm{c}}$ \\
& AST and ALT $\leq 10$ & AND & $\leq 1.5$ & $32^{\mathrm{c}}$ \\
Moderate hepatic impairment & AST and ALT $\leq 10$ & AND & $>1.5$ to $\leq 3$ & $20-30^{\mathrm{c}}$ \\
\hline
\end{tabular}

aExcluding patients whose total bilirubin is elevated due to Gilbert's disease.

${ }^{\mathrm{b}}$ Refers to dose of ixabepilone when used as monotherapy.

Ixabepilone in combination with capecitabine is contraindicated in these patients

Abbreviations: ALT, alanine aminotransferase; AST, aspartate aminotransferase; ULN, upper limit of normal. 
Table 5 Common ixabepilone-related adverse events and associated management strategies ${ }^{17}$

\begin{tabular}{|c|c|c|}
\hline Symptom & Adverse event & Management strategy \\
\hline \multicolumn{3}{|l|}{ Myelosuppression } \\
\hline Low white blood cell count & Neutrophil count $<500 / \mathrm{mm}^{3} \geq 7 \mathrm{~d}$ & Dose reduction (20\%) \\
\hline Fever & Febrile neutropenia & Dose reduction (20\%) \\
\hline $\begin{array}{l}\text { Signs of infection (chills, cough, } \\
\text { burning, or pain during urination) }\end{array}$ & $\begin{array}{l}\text { Platelet count }<25,000 / \mathrm{mm}^{3} \\
\text { or }<50,000 / \mathrm{mm}^{3} \text { with bleeding }\end{array}$ & Dose reduction (20\%) \\
\hline \multicolumn{3}{|l|}{ Neuropathy } \\
\hline $\begin{array}{l}\text { Numbness, tingling, burning in } \\
\text { hands or feet }\end{array}$ & $\begin{array}{l}\text { Moderate grade } 2 \text { neuropathy } \geq 7 \mathrm{~d} \\
\text { Severe grade } 3 \text { neuropathy }<7 \mathrm{~d} \\
\text { Severe grade } 3 \text { neuropathy } \geq 7 \mathrm{~d} \text { or } \\
\text { disabling neuropathy }\end{array}$ & $\begin{array}{l}\text { Dose reduction }(20 \%) \\
\text { Dose reduction }(20 \%) \\
\text { Discontinue treatment }\end{array}$ \\
\hline \multicolumn{3}{|l|}{ Allergic reactions during infusion } \\
\hline $\begin{array}{l}\text { Itching, hives, or rash } \\
\text { Flushed face }\end{array}$ & All patients (no adverse event) & $\begin{array}{l}\text { Premedication with } \mathrm{H}_{1} \text { and } \mathrm{H}_{2} \text { antagonists } \\
\text { I h prior to infusion }\end{array}$ \\
\hline $\begin{array}{l}\text { Sudden swelling of the face, throat, } \\
\text { or tongue } \\
\text { Tightness in chest, difficulty breathing }\end{array}$ & $\begin{array}{l}\text { Previous hypersensitivity reaction } \\
\text { to ixabepilone }\end{array}$ & $\begin{array}{l}\text { Premedication with corticosteroids } \\
\text { (eg, dexamethasone } 20 \mathrm{mg} \mathrm{IV}, 30 \mathrm{~min} \text { prior } \\
\text { to infusion or orally, } 60 \mathrm{~min} \text { prior to infusion) }\end{array}$ \\
\hline $\begin{array}{l}\text { Faint or feeling of dizziness } \\
\text { Heart palpitations }\end{array}$ & Severe hypersensitivity reaction & $\begin{array}{l}\text { Stop treatment and begin aggressive } \\
\text { supportive treatment (eg, epinephrine, } \\
\text { corticosteroids) }\end{array}$ \\
\hline
\end{tabular}

Abbreviation: IV, intravenous.

of symptom onset and progression. ${ }^{17,32,35}$ Patients should be informed of the importance of proactive reporting of their neuropathy-associated symptoms (eg, numbness, tingling, or burning sensations in the hands or feet) before significant progression occurs. ${ }^{32,37}$ The potential risk of ischemic and thermal injuries due to loss of sensation in the extremities should also be emphasized. ${ }^{37}$

Patients with paclitaxel-induced neuropathic pain have experienced symptomatic relief with the use of amitriptyline 10 to $50 \mathrm{mg} .{ }^{30} \mathrm{~A}$ number of neuroprotective agents (eg, glutamine, glutathione, vitamin E, acetyl-L-carnitine, calcium, and magnesium) are being investigated for the prevention of neurotoxic injury; however, the clinical utility of these agents remains largely unknown. ${ }^{36-38}$ In a clinical study designed to assess the neuroprotective effects of glutamine in patients receiving high-dose paclitaxel, glutamine was associated with a significant reduction in the severity of peripheral neuropathy and had positive effects on toe and finger numbness, motor weakness, and vibratory sensation. ${ }^{39}$ Additional nonpharmacologic interventions (eg, exercise, physical therapy, massage) and the use of suggested self-care measures (eg, avoidance of extreme temperatures and other stimuli, and regular inspections of feet for injury) may enhance patient quality of life and safety. ${ }^{32,35,37}$

\section{Myalgia and arthralgia}

Myalgia and arthralgia are among the most common nonhematologic AEs observed during treatment with agents that target microtubules, but their etiology and associated management techniques are underrepresented in the oncology literature compared to other common toxicities. ${ }^{40}$ Ixabepilone-associated myalgias and arthralgias are typically moderate in severity; while dose reduction is usually not necessary for transient myalgia/arthralgia, ongoing events may require intervention, and any $\mathrm{AE}$ deemed disabling warrants treatment discontinuation. ${ }^{17}$

Risk factors for myalgia and arthralgia are similar to those for peripheral neuropathy, ${ }^{29}$ so patients should be assessed for these AEs as well. Myalgia and arthralgia differ from neuropathic pain in both presentation and recommended treatment, and practitioners should bear this point in mind when assessing patients for cancer-related pain. Patients often describe myalgias and arthralgias as dull, poorly localized aches, the former in large axial muscles, arms, and legs, and the latter in limb joints. As mentioned above, arthralgias and myalgias may be exacerbated by hematopoietic growth factor use, which is itself associated with flulike aches. ${ }^{29}$

Chemotherapy-related myalgias and arthralgias are thought to have an inflammatory component, and agents such as nonsteroidal anti-inflammatory drugs (NSAIDs), antihistamines, and opiates have proven effective at managing taxane-induced arthralgias and myalgias. ${ }^{29}$ Gabapentin $300 \mathrm{mg}$ administered 3 times daily (tid) for 2 days before and 5 days after infusion has also been shown to reduce taxane-associated myalgia/ arthralgia, while gabapentin $400 \mathrm{mg}$ tid has demonstrated relief of paclitaxel-induced severe myalgia. ${ }^{12}$ Notably, gabapentin 
may not be as effective for the treatment of ixabepilone-related neuropathic pain, ${ }^{41}$ emphasizing the importance of accurate cancer pain assessment during therapy.

\section{Fatigue}

An overwhelming majority of cancer patients experience fatigue, and this $\mathrm{AE}$ is typically the result of multiple underlying causes related to treatment, other comorbidities, or the cancer itself. ${ }^{42}$ Fatigue associated with ixabepilone is usually mild to moderate in severity, and dose reduction is usually not necessary. ${ }^{17}$

Use of exercise to manage chemotherapy-related fatigue is well supported by studies in cancer patients, and it is currently the only intervention rated as "Recommended for Practice" by the current Oncology Nursing Society (ONS) fatigue guidelines (available at www.ons.org). Although additional research is needed to determine which types of exercise are most effective in which patient populations, it is clear that exercise need not be complex or high intensity to be beneficial. The appropriate exercises, as well as their intensity and duration, should be determined on a case-by-case basis after considering the patient's overall level of functionality, comorbidities, confounding AEs (eg, myelosuppression that results in low white blood cell or platelet counts), and personal preference. ${ }^{42,43}$ As with any intervention, exercise routines should be monitored carefully throughout the patient's course of treatment.

At present, insufficient data preclude the recommendation of any pharmacological agents for the treatment of chemotherapyassociated fatigue, and the ONS categorizes pharmacological interventions for fatigue under "Effectiveness Not Established." Multiple agents have demonstrated some level of efficacy in clinical trials: psychostimulants (eg, methylphenidate and dexmethylphenidate), antidepressants (eg, paroxetine, bupropion), progestational agents, and corticosteroids, ${ }^{42,43}$ although some of these agents carry their own risk of AEs that may outweigh the benefits.

Fatigue can stem from or be influenced by other issues related to the cancer (autonomic dysfunction, altered hormone, or interleukin secretion) or the chemotherapy regimen (anemia, pain, sleep disturbance, emotional distress). As such, proactive monitoring and management of other treatment-related AEs may alleviate or lessen fatigue. ${ }^{42-44}$

\section{Hypersensitivity reactions}

Cremophor EL, used as a diluent for water-insoluble drugs, is associated with its own spectrum of AEs, including severe anaphylactoid hypersensitivity reactions, hyperlipidemia, abnormal lipoprotein patterns, erythrocyte aggregation, and peripheral neuropathy. ${ }^{45}$ Ixabepilone is currently formulated with Cremophor EL, although less of this diluent is required than is necessary for standard taxane formulations. ${ }^{17,46}$ Among all patients with $\mathrm{MBC}$ who received ixabepilone in the clinical studies that led to its FDA approval $(n=1323)$, only nine $(1 \%)$ of these patients had severe hypersensitivity reactions. ${ }^{17,19,20}$

To prevent severe hypersensitivity reactions to the Cremophor vehicle, patients receiving ixabepilone should be premedicated with an $\mathrm{H}_{1}$ (eg, diphenhydramine $50 \mathrm{mg}$ orally or equivalent) and an $\mathrm{H}_{2}$ (eg, ranitidine 150 to $300 \mathrm{mg}$ orally or equivalent) antagonist approximately 1 hour prior to infusion (Table 5). ${ }^{17}$ In contrast to the taxanes, prophylactic premedication with steroids is not required for all patients receiving ixabepilone. However, patients who have previously experienced hypersensitivity reactions during ixabepilone therapy require premedication with high-dose corticosteroids (eg, dexamethasone $20 \mathrm{mg} I V, 30$ minutes before infusion or orally, 60 minutes before infusion) in addition to pretreatment with $\mathrm{H}_{1}$ and $\mathrm{H}_{2}$ antagonists prior to subsequent dosing (Table 5). ${ }^{17}$ Prolonging the infusion time during treatment may further minimize the risk of hypersensitivity reactions. If severe hypersensitivity reactions do occur, the ixabepilone infusion should be stopped and aggressive supportive treatment (eg, epinephrine and corticosteroids) initiated. Patients with a history of severe hypersensitivity reactions to agents containing Cremophor EL should not be treated with ixabepilone. ${ }^{17}$

\section{Dosing and administration}

Ixabepilone is formulated for IV administration, and the recommended dose is $40 \mathrm{mg} / \mathrm{m}^{2}$ infused over 3 hours every 3 weeks. Dosing in patients with a body surface area of greater than $2.2 \mathrm{~m}^{2}$ should be calculated based on a value of $2.2 \mathrm{~m}^{2}$. Ixabepilone is supplied as a white powder in sterile, single-use 15- or 45-mg vials, packaged as a kit with a vial of premeasured diluent $(52.8 \% \mathrm{w} / \mathrm{v}$ purified polyoxyethylated castor oil and 39.8\% w/v dehydrated alcohol, USP). For optimal stability, ixabepilone is further diluted to its suggested final concentration ( 0.2 to $0.6 \mathrm{mg} / \mathrm{mL}$ ) with Lactated Ringer's Injection, USP (LRI), normal saline (NS, pH adjusted with sodium bicarbonate), or Plasma-Lyte A Injection, pH 7.4, prior to administration. ${ }^{17,47}$ LRI has been used as a diluent due to its $\mathrm{pH}$ range of 6.0 to 7.5 , because the stability of ixabepilone has been shown to decrease up to 3-fold in lower $\mathrm{pH}$ solutions,${ }^{17}$ however, the FDA approved the use of these two alternative diluents for ixabepilone in $2009 .{ }^{47}$ When using a $250-\mathrm{mL}$ or $500-\mathrm{mL}$ bag of NS (in the form of $0.9 \%$ Sodium Chloride Injection, USP) to prepare the infusion, the $\mathrm{pH}$ must be adjusted to between 6.0 and 9.0. To adjust the $\mathrm{pH}$, 
add 2 molar equivalents (ie, $2 \mathrm{~mL}$ of an $8.4 \% \mathrm{w} / \mathrm{v}$ solution or $4 \mathrm{~mL}$ of a $4.2 \% \mathrm{w} / \mathrm{v}$ solution) of Sodium Bicarbonate Injection, USP, prior to adding the constituted ixabepilone solution. Importantly, di-(2-ethylhexyl)phthalate (DEHP)-free solution bags, infusion containers, and administration sets must be used. The final infusion solution is administered using an in-line filter with a 0.2 to $1.2 \mu \mathrm{m}$ microporous membrane within 6 hours of preparation.

\section{Conclusion}

Because of the high rates of tumor resistance observed with available chemotherapeutic agents, optimal management of $\mathrm{MBC}$ is a significant challenge to healthcare professionals. Ixabepilone, a novel MSA that is structurally and pharmacologically distinct from taxanes, was recently approved by the FDA as monotherapy or in combination with capecitabine for the treatment of resistant MBC. This approval was based on the results of several clinical studies that demonstrated a manageable safety profile and substantial antitumor activity of ixabepilone in patients with treatmentresistant $\mathrm{MBC}$. Clinical studies evaluating ixabepilone for the treatment of other cancer types are ongoing and, in some cases, suggest promising antitumor activity. As such, healthcare professionals will most likely encounter an increasing number of patients who may be candidates for ixabepilone therapy.

Treatment-related AEs were similar to those observed with many other chemotherapeutic agents and included primarily hematologic toxicity (eg, neutropenia and leukopenia) and sensory neuropathy. Ixabepilone-related AEs were predictable and were managed with dose modification or delay. Importantly, proactive intervention and patient education can aid in identifying ixabepilone-associated AEs before they progress to severe events. As a result, healthcare providers can intervene with dose modification and other interventions, increasing the likelihood that patients will remain on treatment for a longer period of time without significantly disrupting their overall quality of life. The introduction of ixabepilone to the armamentarium of MBC treatment options represents an exciting new era for patients, particularly those with taxane-resistant MBC who currently have few treatment options.

\section{Acknowledgments}

The authors take full responsibility for the content of this publication and confirm that it reflects their viewpoint and medical expertise. They also wish to acknowledge StemScientific and MedErgy, funded by Bristol-Myers Squibb, for providing writing and editing support. Bristol-Myers Squibb did not influence the content of the manuscript, nor did the authors receive financial compensation for authoring the manuscript.

\section{References}

1. American Cancer Society. Cancer facts and figures 2008. [Cited on Mar 13, 2009]. Available from: http://www.cancer.org.

2. Jemal A, Siegel R, Ward E, et al. Cancer statistics, 2008. CA Cancer J Clin. 2008;58(2):71-96.

3. American Cancer Society. Breast cancer facts and figures 2007-2008. [Cited on Mar 13, 2009]. Available from: http://www.cancer.org. Accessed March 13, 2009.

4. Beslija S, Bonneterre J, Burstein H, et al. Second consensus on medical treatment of metastatic breast cancer. Ann Oncol. 2007;18(2):215-225.

5. Fojo AT, Menefee M. Microtubule targeting agents: basic mechanisms of multidrug resistance (MDR). Semin Oncol. 2005;32(6 Suppl 7):S3-S8.

6. Geney R, Ungureanu M, Li D, Ojima I. Overcoming multidrug resistance in taxane chemotherapy. Clin Chem Lab Med. 2002;40(9):918-925.

7. Rowinsky EK. The development and clinical utility of the taxane class of antimicrotubule chemotherapy agents. Annu Rev Med. 1997;48:353-374.

8. Valero V, Hortobagyi GN. Are anthracycline-taxane regimens the new standard of care in the treatment of metastatic breast cancer? J Clin Oncol. 2003;21(6):959-962.

9. Gonzalez-Angulo AM, Morales-Vasquez F, Hortobagyi GN. Overview of resistance to systemic therapy in patients with breast cancer. $A d v$ Exp Med Biol. 2007;608:1-22.

10. Kamath K, Wilson L, Cabral F, Jordan MA. BetaIII-tubulin induces paclitaxel resistance in association with reduced effects on microtubule dynamic instability. J Biol Chem. 2005;280(13):12902-12907.

11. Polli JW, Humphreys JE, Harmon KA, et al. The role of efflux and uptake transporters in [N-\{3-chloro-4-[(3-fluorobenzyl)oxy]phenyl $\}-6-$ [5-(\{[2-(methylsulfonyl)ethyl]amino\}methyl)-2-furyl]-4-quinazolinamine (GW572016, lapatinib) disposition and drug interactions. Drug Metab Dispos. 2008;36(4):695-701.

12. Lee JJ, Swain SM. Development of novel chemotherapeutic agents to evade the mechanisms of multidrug resistance (MDR). Semin Oncol. 2005;32(6 Supp1 7):S22-S26.

13. Bollag DM, McQueney PA, Zhu J, et al. Epothilones, a new class of microtubule-stabilizing agents with a taxol-like mechanism of action. Cancer Res. 1995;55(11):2325-2333.

14. Cortes J, Baselga J. Targeting the microtubules in breast cancer beyond taxanes: the epothilones. Oncologist. 2007;12(3):271-280.

15. Nettles JH, Li H, Cornett B, Krahn JM, Snyder JP, Downing KH. The binding mode of epothilone A on alpha,beta-tubulin by electron crystallography. Science. 2004;305(5685):866-869.

16. Fornier MN. Ixabepilone, first in a new class of antineoplastic agents: the natural epothilones and their analogues. Clin Breast Cancer. 2007;7(10):757-763.

17. Ixempra [package insert]. Princeton (NJ): Bristol-Myers Squibb Company; 2009.

18. Lee FY, Wen ML, Shen H, et al. Ixabepilone overcomes multiple mechanisms of drug resistance including overexpression of class III $\beta$-tubulin and breast cancer resistance protein. Presented at the 2008 European Breast Cancer Conference; 2008 Apr 15-19; Berlin, Germany.

19. Perez EA, Lerzo G, Pivot X, et al. Efficacy and safety of ixabepilone (BMS-247550) in a phase II study of patients with advanced breast cancer resistant to an anthracycline, a taxane, and capecitabine. J Clin Oncol. 2007;25(23):3407-3414.

20. Thomas ES, Gomez HL, Li RK, et al. Ixabepilone plus capecitabine for metastatic breast cancer progressing after anthracycline and taxane treatment. J Clin Oncol. 2007;25(33):5210-5217.

21. Hortobagyi GN, Perez E, Vrdoljak E, et al. Analysis of overall survival (OS) among patients (pts) with metastatic breast cancer (MBC) receiving either ixabepilone (I) plus capecitabine (C) or C alone: results from two randomized phase III trials. Presented at the 2008 ASCO Breast Cancer Symposium; 2008 Sept 5-7; Washington, DC. Abstract 186. 
22. Roché H, Yelle L, Cognetti F, et al. Phase II clinical trial of ixabepilone (BMS-247550), an epothilone B analog, as first-line therapy in patients with metastatic breast cancer previously treated with anthracycline chemotherapy. J Clin Oncol. 2007;25(23):3415-3420.

23. Thomas E, Tabernero J, Fornier M, et al. Phase II clinical trial of ixabepilone (BMS-247550), an epothilone B analog, in patients with taxane-resistant metastatic breast cancer. J Clin Oncol. 2007;25(23):3399-3406.

24. Montoya L. Managing hematologic toxicities in the oncology patient. J Infus Nurs. 2007;30(3):168-172.

25. Marrs J. Care of patients with neutropenia. Clin J Oncol Nurs. 2006;10(2):164-166.

26. Camp-Sorrell D. Myelosuppression. In: Itano JK, Taoka KN, editors. Core curriculum for oncology nursing. 4th ed. Philadelphia: Elsevier; 2005. p. 259-274.

27. Lyman GH, Lyman $\mathrm{CH}$, Agboola O. Risk models for predicting chemotherapy-induced neutropenia. Oncologist. 2005;10(6): 427-437.

28. Polovich M, White JM, Kelleher LO. Chemotherapy and biotherapy guidelines and recommendations for practice. 2nd ed. Pittsburgh: Oncology Nursing Society; 2005.

29. Martin VR. Arthralgias and myalgias. In: Yarbro $\mathrm{CH}$, Frogge $\mathrm{MH}$, Goodman M, editors. Cancer symptom management. 3rd ed. Sudbury (MA): Jones and Bartlett; 2004. p. 20-25.

30. Lee JJ, Swain SM. Peripheral neuropathy induced by microtubulestabilizing agents. J Clin Oncol. 2006;24(10):1633-1642.

31. Visovsky C, Meyer RR, Roller J, Poppas M. Evaluation and management of peripheral neuropathy in diabetic patients with cancer. Clin $J$ Oncol Nurs. 2008;12(2):243-247.

32. Wickham R. Chemotherapy-induced peripheral neuropathy: a review and implications for oncology nursing practice. Clin J Oncol Nurs. 2007;11(3):361-376

33. Ocean AJ, Vahdat LT. Chemotherapy-induced peripheral neuropathy: pathogenesis and emerging therapies. Support Care Cancer. 2004;12(9):619-625.

34. Perez E, Pivot X, Vrdoljak E, et al. A prospective characterization of the resolution of ixabepilone induced peripheral neuropathy: data from a large registrational program in patients with metastatic breast cancer Presented at the San Antonio Breast Cancer Symposium (SABCS); 2008 Dec 10-14; San Antonio (TX). Poster 6140.
35. Armstrong T, Almadrones L, Gilbert MR. Chemotherapy-induced peripheral neuropathy. Oncol Nurs Forum. 2005;32(2):305-311.

36. Stillman M, Cata JP. Management of chemotherapy-induced peripheral neuropathy. Curr Pain Headache Rep. 2006;10(4):279-287.

37. Visovsky C, Collins M, Abbott L, Aschenbrenner J, Hart C. Putting evidence into practice: evidence-based interventions for chemotherapyinduced peripheral neuropathy. Clin J Oncol Nurs. 2007;11(6): 901-913.

38. Stubblefield MD, Vahdat LT, Balmaceda CM, Troxel AB, Hesdorffer CS, Gooch CL. Glutamine as a neuroprotective agent in high-dose paclitaxelinduced peripheral neuropathy: a clinical and electrophysiologic study. Clin Oncol (R Coll Radiol). 2005;17(4):271-276.

39. Vahdat L, Papadopoulos K, Lange D, et al. Reduction of paclitaxelinduced peripheral neuropathy with glutamine. Clin Cancer Res. 2001;7(5):1192-1197.

40. Markman M. Prevention of paclitaxel-associated arthralgias and myalgias. J Support Oncol. 2003;1(4):233-234.

41. Wilkes GM, Barton-Burke M. Oncology nursing drug handbook. Sudbury (MA): Jones and Bartlett; 2006. p. 205-208.

42. Yennurajalingam S, Bruera E. Fatigue and dyspnea. In: Pazdur R, Goia LR, Hoskins WJ, et al. editors. Cancer management: a multidisciplinary approach. 10th ed. Lawrence (KS): CMPMedica; 2007. p. 917-927.

43. Barsevick AM, Newhall T, Brown S. Management of cancer-related fatigue. Clin J Oncol Nurs. 2008;12 Suppl 5:21-25.

44. Minton O, Richardson A, Sharpe M, et al. A systematic review and meta-analysis of the pharmacological treatment of cancer-related fatigue. J Natl Cancer Inst. 2008;100(16):1155-1166.

45. Gelderblom H, Verweij J, Nooter K, Sparreboom A. Cremophor EL: the drawbacks and advantages of vehicle selection for drug formulation. Eur J Cancer. 2001;37(13):1590-1598.

46. Taxol [package insert]. Princeton (NJ): Bristol-Myers Squibb Company; 2007.

47. Drugs@FDA Web site. IXEMPRA Control Supplement Letter NDA22065/S-001 [updated 2009 March 13; cited 2009 March 30]. Available from http://www.fda.gov/cder/foi/appletter/2009/022065s0011tr.pdf.
Cancer Management and Research

\section{Publish your work in this journal}

Cancer Management and Research is an international, peer-reviewed open access journal focusing on cancer research and the optimal use of preventative and integrated treatment interventions to achieve improved outcomes, enhanced survival and quality of life for the cancer patient The journal welcomes original research, clinical \& epidemiological

\section{Dovepress}

studies, reviews \& evaluations, guidelines, expert opinion \& commentary, case reports \& extended reports. The manuscript management system is completely online and includes a very quick and fair peerreview system, which is all easy to use. Visit http://www.dovepress.com/ testimonials.php to read real quotes from published authors. 